\title{
A Real Scenario for a Ghosting Flame
}

\author{
L. AUDOUIN, J.M. SUCH, J.C. MALET and C. CASSELMAN \\ IPSN/DRS-Laboratoire d'Expérimentation et de Modélisation des Feux \\ C.E. de Cadarache-13108-St Paul lez Durance-France
}

\begin{abstract}
An experimental study is presented of a full- scale compartment fire. The room is $10 \mathrm{~m}$ long, $3.75 \mathrm{~m}$ wide and $2.50 \mathrm{~m}$ high. One end of the room is closed and the other one has an opening of $0.8 \times 0.8 \mathrm{~m}^{2}$ in its center. A pool of TBP/TPH liquid fuel $\left(1 \mathrm{~m}^{2}\right)$ is placed at $2 \mathrm{~m}$ from the closed end in order to simulate an accidental fire of solvents in nuclear plants. These particular conditions result in a fire that is controlled by natural ventilation and the whole room being quickly invaded by combustion products and fuel gases. The temperature in the compartment quickly increases up to about $560^{\circ} \mathrm{C}$. It is then observed that the flame migrates from the original fuel surface towards the opening over a distance of $8 \mathrm{~m}$ with a displacement velocity ranging from 4 to $8 \mathrm{~cm} / \mathrm{s}$. This flame presents characteristics similar to those of the ghosting flame described by Sugawa et al. Then the fire stabilizes at the opening of the room until there is no more liquid fuel available in the pool fire. The collected experimental data consists of temperatures, concentrations of chemical species $\left(\mathrm{O}_{2}\right.$, $\mathrm{CO}_{2}, \mathrm{CO}$ ), pressure in the fire room and recordings by means of a video camera.
\end{abstract}

KEYWORDS : Compartment fires ; Full-scale test ; Ghosting flame ; Poor ventilation ; High temperatures; Species production.

\section{INTRODUCTION}

For well-ventilated conditions, compartment fires are usually characterized by the formation of a hot upper layer of combustion products near the ceiling and a cold lower layer of nonvitiated air near the floor [2]. Such a phenomenon can be described with a good approximation by means of two-zone modeling [1]. Alternatively, it is a common scenario to find a mechanical ventilation system which provides, through air intakes placed near the 
floor, an air supply 2 to 3 times smaller than needed to burn fuel gases produced during the fire $[2,3]$. Under these under-ventilated conditions, the hot upper layer progressively invades all the compartment and a single hot layer is formed from a mixture of air and combustion products. It is then said that the fire is controlled by ventilation and the room on fire has a well-stirred compartment behavior as described by Beyler [3]. A similar behavior has been observed for naturally ventilated compartments with small openings (low natural ventilated conditions) [4,5]. From that moment on, the pool fire burns in a vitiated atmosphere due to the presence of combustion products, which most often leads to extinction of the flame as soon as the oxygen concentration in the gaseous mixture drops below a critical value between $11 \%$ and $15 \%$ expressed in terms of mole fraction $[3,6,7,8]$.

A recent study by Sugawa et $\mathrm{Al}$ [5], dealing with a small-sized room (3 $\mathrm{m}$ long, $2 \mathrm{~m}$ wide and $0.6 \mathrm{~m}$ high) which had in its center a pool fire (methanol) of $0.30 \mathrm{~m}$ in diameter, has shown a behavior of the flame that is not common during the phase preceding fire extinction. As a matter of fact, under natural poorly ventilated conditions (i.e. fuel rich and oxygen poor) and high temperature conditions, the flame separates from the fuel surface and stabilizes below the ceiling ; this phenomenon is called "ghosting fire". Fleishmann et $\mathrm{Al}$ have observed a similar behavior of the flame while conducting experiments on backdraft phenomena $[9,10]$.

This experiment is part of a series of safety studies on industrial and nuclear facilities in which compartments have been confined to avoid leaks of gaseous products hazardous to the environment (toxic products, radioactive particles). It is typical for this type of room to keep air exchanges through the openings relatively low (typically three times as much as the volume of the compartment per hour). Under these conditions, the occurrence of a ghosting fire seems quite likely. From the fire safety point of view, the mechanisms leading to a ghosting fire present an important risk, specially, if it is assumed that the ghosting fire can spread not only towards the ceiling of the compartment [5] but also towards an opening and thus spread the fire to other rooms. In this work, a real scenario for a ghosting fire is presented. The particular case is that of a compartment fire with natural ventilation ensured by a small opening located at one end of a room. A tank containing a liquid fuel is placed near the other end of the room to simulate an accidental fire. The aim of this study is to show the possible migration of a flame from its fuel surface towards the opening of the fire compartment by a process similar to the ghosting fire.

\section{EXPERIMENTAL DESIGN}

\section{Apparatus}

The characteristic dimensions of the compartment used for the experiments are : $10 \mathrm{~m}$ long, $3.75 \mathrm{~m}$ wide and $2.5 \mathrm{~m}$ high, providing a total volume of about $95 \mathrm{~m}^{3}$. One end is closed and the other has an opening of $0.8 \times 0.8 \mathrm{~m}^{2}$ located in the middle of the East wall. A clearer image of the experiment can be obtained from Figure 1. The wall surfaces of the room consist of fireproof fibers : KERANAP fibers $(25 \mathrm{~mm}$ thick) near the pool fire and THERMIPAN fibers ( $40 \mathrm{~mm}$ thick) on the opening side. All fireproof walls are supported by a steel structure. The central axis of the flammable pool is positioned on the symmetry plane of the room at $2 \mathrm{~m}$ from the West wall. A port hole to observe the burning pool has been 
placed up on the South wall at a distance of $2 \mathrm{~m}$ from the West wall (coinciding with the pool central axis). A second camera was placed outside the East wall to film the compartment opening.

Figure $1:$ Schematics of the fire compartment

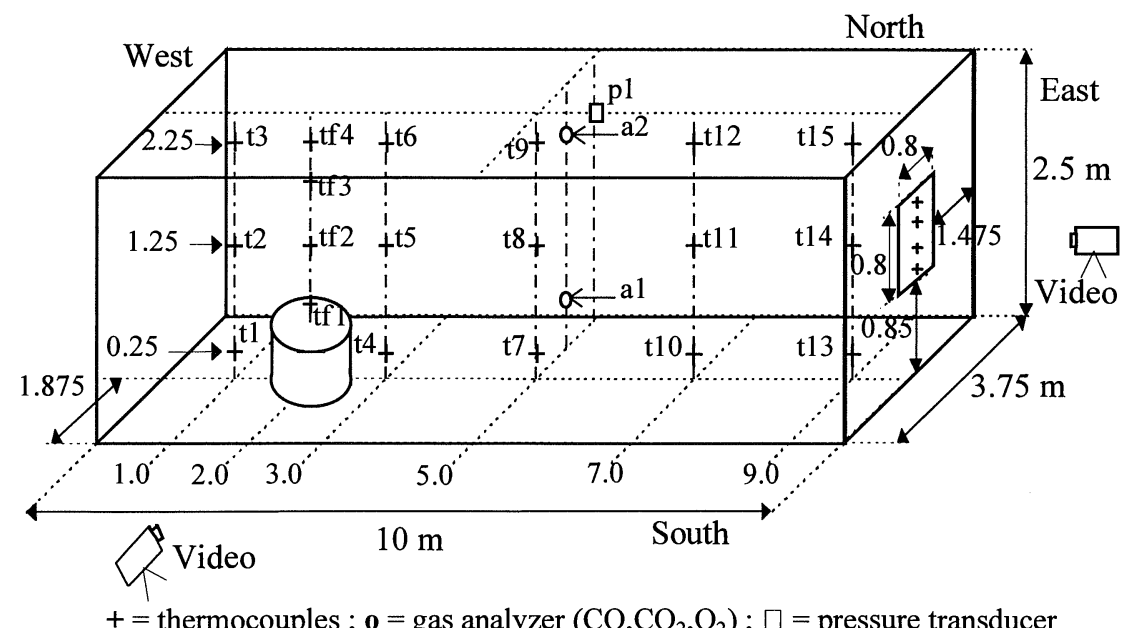

Figure 2 : Schematic diagram of the fire room inside the JUPITER facility $\left(3600 \mathrm{~m}^{3}\right)$

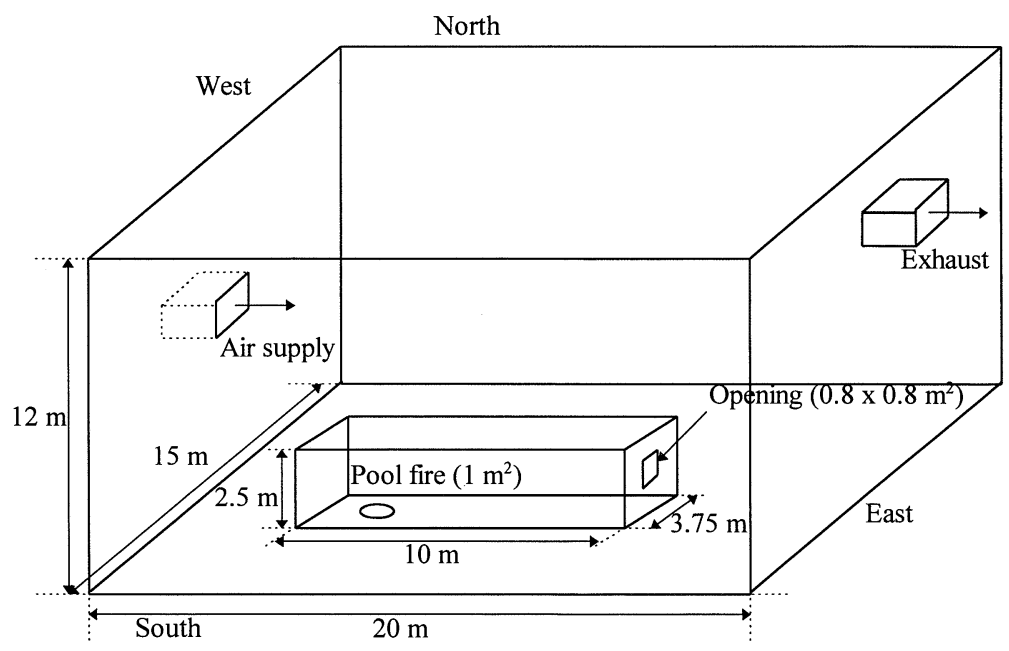


This fire compartment was placed in a large experimental facility $\left(3600 \mathrm{~m}^{3}\right)$, called JUPITER (Figure 2). The air inlets and outlets of this experimental facility are controlled by a network of industrial ventilation which allows to evacuate the combustion products released through the opening of the fire room. The ventilation operating conditions allow a volume flow rate of $18000 \mathrm{~m}^{3} / \mathrm{h}$ under steady operating conditions (initial conditions of the experiment). For safety reasons, a nitrogen injection system can provide a large flow rate that is capable, if necessary, of rapidly depleting the oxygen of this JUPITER facility.

\section{Fuel}

The fuel is a mixture of liquid hydrocarbons, $70 \%$ of Hydrogenated TetraPropylene [TPH $\left.\left(\mathrm{C}_{12} \mathrm{H}_{26}\right)\right]$ and $30 \%$ of TriButylPhosphate - [TBP $\left.\left(\left(\mathrm{C}_{4} \mathrm{H}_{9}\right)_{3} \mathrm{PO}_{4}\right)\right]$ in volume. Its main characteristics are : $\rho=816 \mathrm{~kg} / \mathrm{m}^{3}$ and heat of combustion : $\Delta H_{R}=36 \mathrm{MJ} / \mathrm{kg}$. The flash point of TBP/TPH is $55^{\circ} \mathrm{C}$ (class II of flammable liquids - US Classification [11]). The circular tank containing the liquid fuel has a surface area of $1 \mathrm{~m}^{2}$ and is located on the central axis of the compartment at $2 \mathrm{~m}$ from the West wall (Figure 1). In order to measure the evolution of the fuel mass flow, the tank is placed on three scales. The initial position of the fuel surface is at $0.50 \mathrm{~m}$ above the floor. The load cell is heat-insulated to minimize thermal stresses during the experiment. The initial quantity of TBP/TPH liquid fuel is of 50 liters.

\section{Species Concentration}

In order to characterize the chemical conditions of the compartment during the experiment, the temporal evolution of the species concentration is recorded. Concentrations by volume are obtained for: oxygen $\left(\mathrm{O}_{2}\right)$, carbon dioxide $\left(\mathrm{CO}_{2}\right)$ and carbon monoxide $(\mathrm{CO})$. Continuous sampling of gases is accomplished by means of two non-cooled stainless steel sintered probes ; each sampling probe supplies all gas analyzers (OH831-ICARE for $\mathrm{O}_{2}$, ULTRAMAT 22P-SIEMENS for $\mathrm{CO}$ and $\mathrm{CO}_{2}$ ). One probe (noted a1) is located in the lower part of the room, at $5 \mathrm{~m}$ from the opening, $0.5 \mathrm{~m}$ from the floor and $1 \mathrm{~m}$ from the North wall. The other probe (noted a2) is located above the first one, at $0.5 \mathrm{~m}$ from the top of the room.

\section{Temperatures}

Temperatures are measured in the room by means of sheathed thermocouples, type $\mathrm{K}$ and $0.2 \mathrm{~mm}$ in diameter. All the temperatures reported here are uncorrected values. Five vertical thermocouple holders are placed at $1 \mathrm{~m}, 3 \mathrm{~m}, 5 \mathrm{~m}, 7 \mathrm{~m}$ and $9 \mathrm{~m}$ from the West wall. Each holder supports three thermocouples at $0.25,1.25$ and $2.25 \mathrm{~m}$ from the floor and are presented in Figure 1 (noted 11 to 113 ). The thermocouples allow observation of the displacement of hot gases along the longitudinal axis of the compartment. At the level of the opening, four thermocouples are positioned vertically at $0.10 \mathrm{~m}, 0.30 \mathrm{~m}, 0.50 \mathrm{~m}$ and $0.70 \mathrm{~m}$ from the base of the opening (at the symmetry plane). A final thermocouple holder is placed on the vertical axis of the pool fire with thermocouples placed at $0.25 \mathrm{~m}, 0.75 \mathrm{~m}, 1.25 \mathrm{~m}$ and 
$1.75 \mathrm{~m}$ above the initial level of the fuel (noted tf1 to tf4). These thermocouples measure the temperatures in the flame zone.

\section{Compartment pressure}

The pressure evolution in the compartment is recorded by means of a ROSEMOUNT electronic pressure transducer with an effective range of -10 to $50 \mathrm{hPa}$. The pressure port is mounted in the center of the room, at $0.10 \mathrm{~m}$ from the North wall and $0.50 \mathrm{~m}$ from the ceiling (noted p1). The ambient reference pressure is taken in the JUPITER facility.

\section{Data acquisition system}

Data acquisition is carried out by means of a HP VECTRA ES/12 micro-computer via an acquisition processing unit HP $3852 \mathrm{~A}$ and HP 3853A. The mean acquisition frequency is of $1 \mathrm{scan} / \mathrm{s}$.

\section{PROCEDURE}

The TBP/TPH mixture is prepared only a few hours before the experiment in order to obtain a liquid fuel mixture as homogeneous as possible. Once the tank has been filled up with the flammable mixture, data acquisition is started followed by the ventilation system of the JUPITER facility. As soon as steady operating conditions are attained, thus defining the initial conditions of the experiment, a propane burner, used as a pilot flame, ignites the fuel surface at one edge of the tank. Once ignition is accomplished, this one is turned off and the flame spreads all over the flammable pool. After the fire is extinguished, data acquisition will remain in operation in order to study the cooling phase of the room. It is assumed that the experiment is over when the temperature is less than $30^{\circ} \mathrm{C}$ in the whole compartment.

\section{RESULTS}

An important parameter in a compartment fire is the heat rate released by the burning pool, which can be obtained approximately by measuring fuel weight loss versus time. Unfortunately, the scales have been damaged by the thermal stresses during the fire experiment. Thus, an overall balance of weight loss between the fuel mass $\left(m_{f}\right)$ before the experiment $\left(\mathrm{m}_{\mathrm{f}}=40.8 \mathrm{~kg}, \mathrm{t}_{\mathrm{ini}}=0 \mathrm{~s}\right)$ and the mass of carbonaceous residue measured after the fire $\left(\mathrm{m}_{\mathrm{f}}=2.5 \mathrm{~kg}, \mathrm{t}_{\mathrm{fin}}=1720 \mathrm{~s}\right)$ can be obtained and shows a mean fuel mass flow $\left(\dot{m}_{f}\right)$ of $0.022 \mathrm{~kg} / \mathrm{s}$. If we suppose that the average heat released by the flame should be written as :

$$
\overline{\Delta H_{R}}=\frac{\Delta m_{f}}{\Delta t}\left(\Delta H_{R}-\Delta H_{V}\right)
$$


Figure 3 : Smoke layer history obtained by video recording

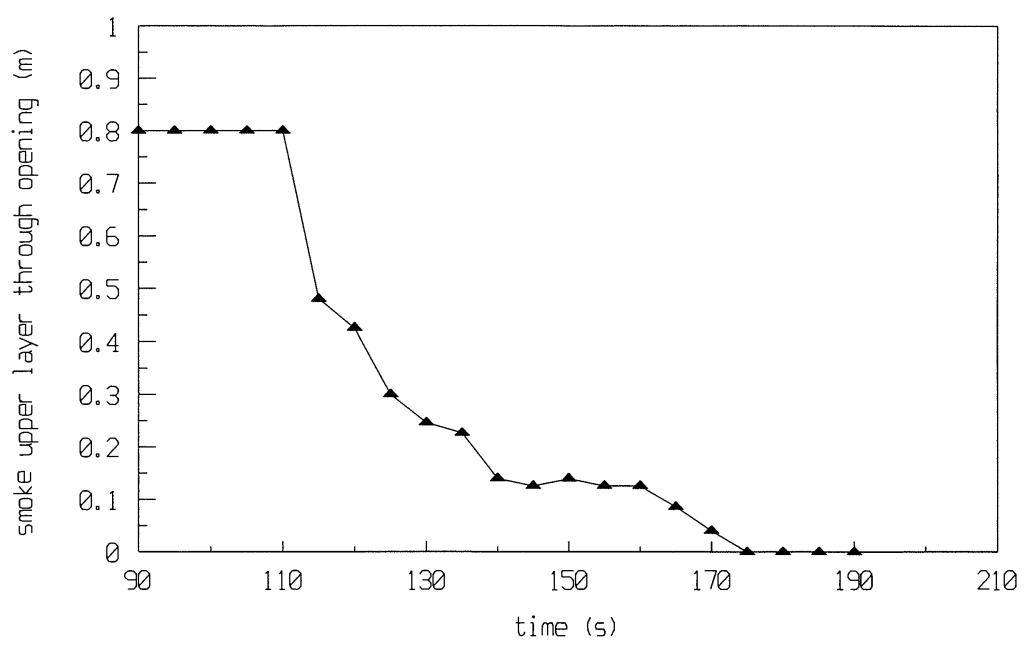

in which the second term to the left is the heat of vaporization $\left(\Delta H_{V}=0.29 \cdot 10^{6} \mathrm{~J} / \mathrm{kg}\right)$, the mean heat release rate is of about $800 \mathrm{~kW}$ during the experiment.

At $t=90 \mathrm{~s}$, the liquid fuel is ignited by a pilot flame obtained by the propane burner. Then, the flame spreads all over the liquid pool in about $10 \mathrm{~s}$. By means of the video camera filming the opening of the room, a black and thick smoke layer with hot gases and soot issuing from the pool fire is observed to impinge the upper part of the room and progress under the ceiling towards the opening. At $20 \mathrm{~s}$ after the beginning of the fire, the smoke upper layer appears at the opening and rapidly exhausts from the compartment to the JUPITER facility. Then this smoke upper layer comes down quickly towards the bottom of the room, as presented in Figure 3 on which the y-coordinate shows the visible boundary of the smoke layer moving from the top to the bottom of the opening. At $t=175 \mathrm{~s}$, the interior walls of the compartment are no longer visible through the opening. These visual observations are in agreement with the sharp temperature increase measured by the thermocouples located at the opening (Figure 4). At this point, the combustion products are released nearly all over the surface of opening, limiting the income of fresh air into the fire room. Figure 5 shows the pressure evolution in the fire room. From the beginning of the fire, an over pressure in the room of about $6 \mathrm{~Pa}$ reduces the inlet air exchange from the JUPITER facility to the fire room. This over pressure remains until the fire is extinguished. The temperature of the top of the compartment (thermocouple noted t9) rises quickly to reach a maximum of $760^{\circ} \mathrm{C}$ at $\mathrm{t}=250 \mathrm{~s}$, i.e. $160 \mathrm{~s}$ after ignition. After this peak, the temperature drops suddenly to reach $640^{\circ} \mathrm{C}$ at $\mathrm{t}=300 \mathrm{~s}$ as the compartment loses energy through its walls and the intensity of the fire begins to be limited by the lack of oxygen (Figure 6). All the thermocouples of the room present the same behavior during this period of time ranging from $90 \mathrm{~s}$ to $300 \mathrm{~s}$ (Figures 7 and 8). During this same period, the $\mathrm{O}_{2}$ concentration in the upper zone drops from $21 \%$ to $0 \%$ and that of the lower zone down to $12.5 \%$ at $t=300 \mathrm{~s}$. 
Figure 4 : Temperature histories at the opening of the compartment

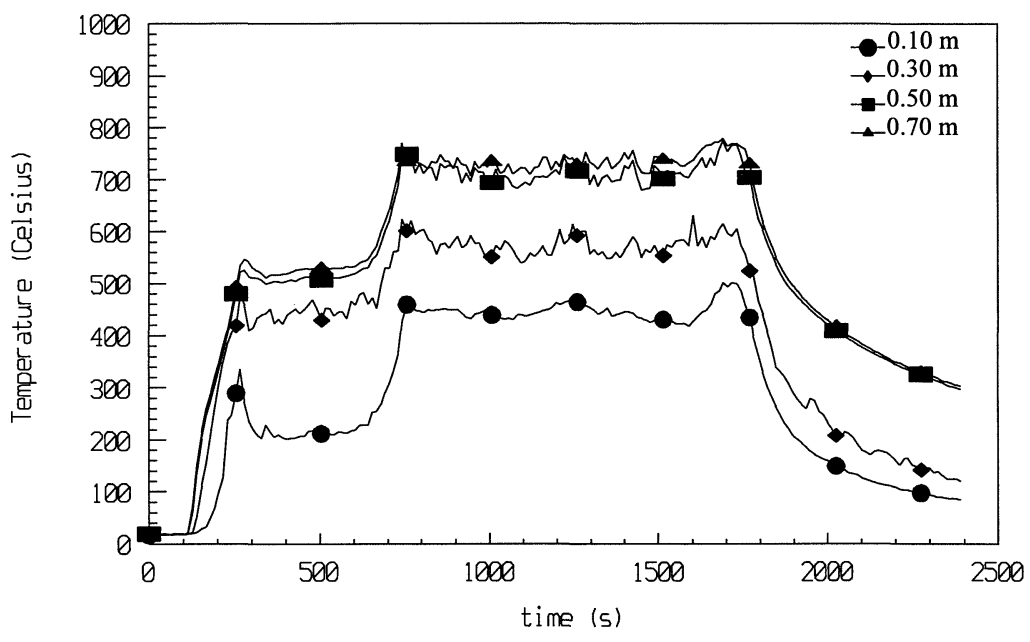

Figure 5 : Pressure evolution in the compartment

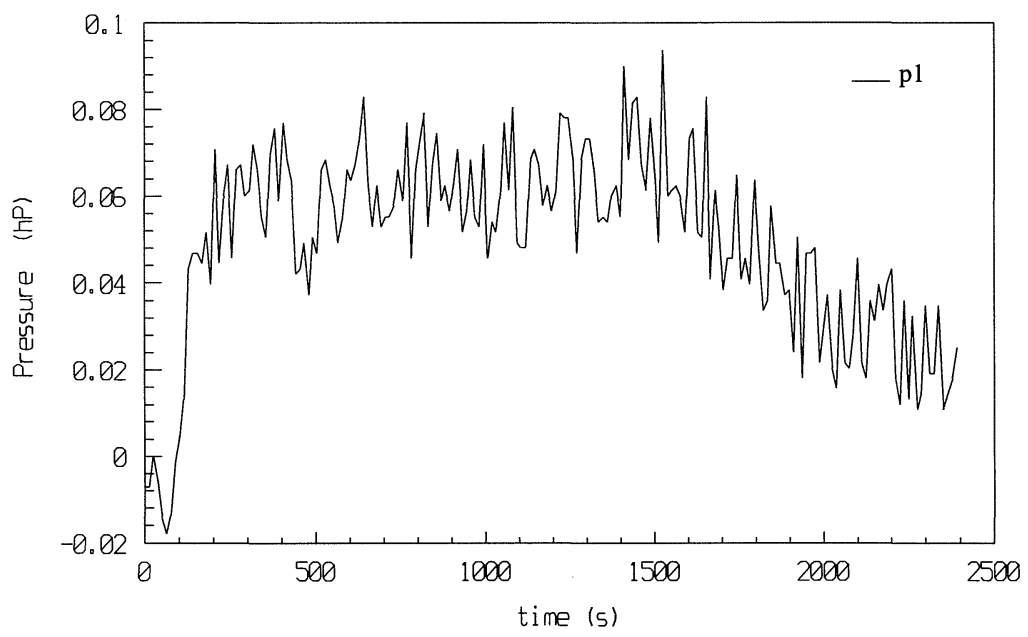

The $\mathrm{CO}$ and $\mathrm{CO}_{2}$ concentrations respectively reach $1 \%$ and $13.5 \%$ in the upper zone and $1 \%$ and $11 \%$ in the lower zone (Figure 6). As the $\mathrm{CO}$ analyzer ranges between $0-1 \%$, the $\mathrm{CO}$ concentration measurement only indicates that the $\mathrm{CO}$ volume fraction in the room exceeds $1 \%$. Consequently, during this first step that shows the beginning of the experiment (step a in Figure 9), the fire is quickly controlled by the natural ventilation of the room, which 
strongly limits the air inlets at the opening. The pool fire is then in a vitiated atmosphere, poor in oxygen and rich in combustion products $\left(\mathrm{CO}_{2}, \mathrm{CO}\right.$ and soot) corresponding to mode 3 described by Morehart et Al. [7]. This mode can lead to the extinction of the flame by lack of oxygen.

Figure 6 : Species concentration histories for the lower and upper zones of the compartment

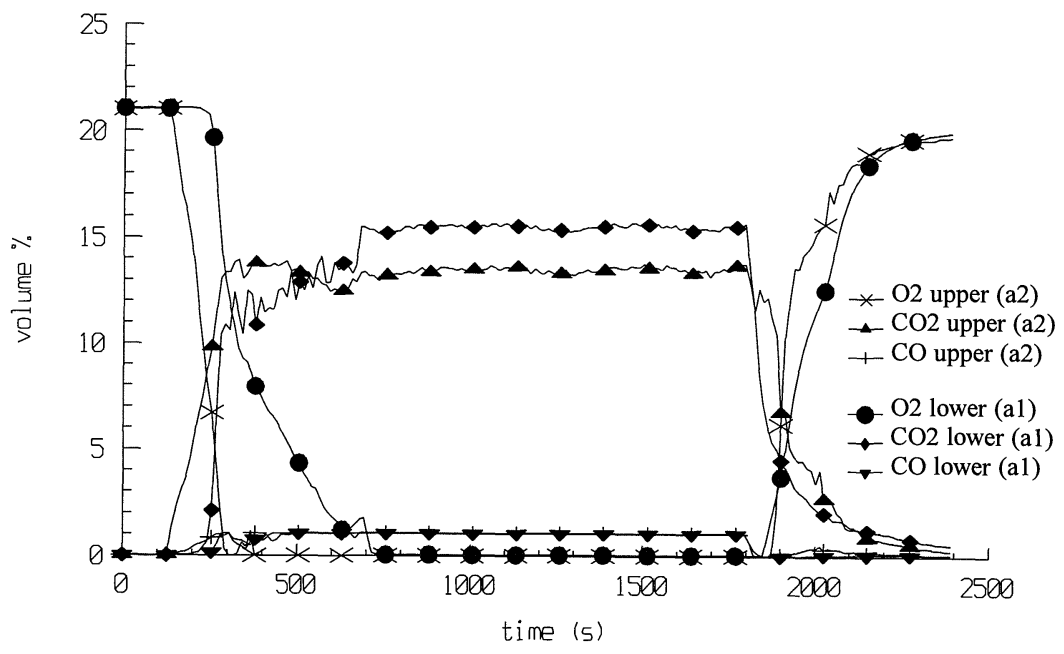

Figure 7 : Vertical temperature evolution at the room center

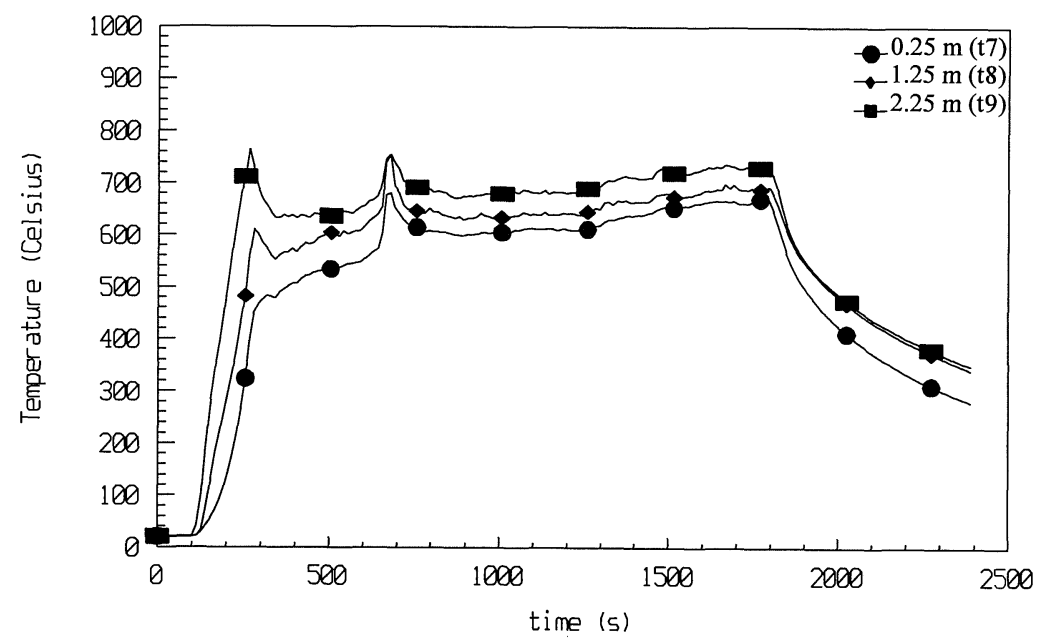


During the second step ranging from $t=300 \mathrm{~s}$ to $600 \mathrm{~s}$ (noted step $\mathrm{b}$ in Figure 9), the temperatures measured in the fire compartment and at the opening do not evolve much (Figures 4, 7 and 8); on the other hand, in the center of the room, the $\mathrm{O}_{2}$ concentration in the lower zone keeps decreasing to reach about $2 \%$ at $\mathrm{t}=600 \mathrm{~s}$ and the $\mathrm{CO}_{2}$ concentration increases to reach nearly the same volume fraction than the upper zone. Considering the very low $\mathrm{O}_{2}$ concentration in the room, one can assume that the flame is below its extinction limit, usually assessed between $10 \%$ and $15 \%$ for most hydrocarbons $[3,6,7,11]$. However, the temperature curves close to the pool fire (Figure 8) indicate that the flame is probably not extinguished. The high temperatures measured in the compartment $\left(>560^{\circ} \mathrm{C}\right.$ - Figure 8) due to adiabatic walls and low air exchange at the opening can explain this behavior. As observed by Sugawa et Al. [5], this experimental result seems to show that the upper flammability limit varies significantly with ambient temperature and that the flame can exist under very lean oxygen concentration conditions.

During the third step ranging from $t=600 \mathrm{~s}$ to $750 \mathrm{~s}$ (noted step $\mathrm{c}$ in Figure 9), the flame detaches itself from the flammable surface and starts migrating through the compartment to the opening. The successive temperature peaks between the tank containing the liquid fuel and the opening (Figure 8) show a displacement of the flame over a distance of about $8 \mathrm{~m}$. This reactive zone moving through the compartment is similar to a ghosting fire characterized by a flame detached from its flammable surface, an environment with a vitiated atmosphere (very poor in oxygen) and with a high temperature, as previously emphasized by Sugawa and $\mathrm{Al}$ [5]. It is assessed that the displacement velocity $\mathrm{V}_{\mathrm{f}}$ of this reactive zone ranges between 4 and $8 \mathrm{~cm} / \mathrm{s}$ and the thickness of the reactive zone would be about $1 \mathrm{~m}$. During the passage of the reactive zone to the center of the room, the $\mathrm{O}_{2}$ volume concentration decreases from $2 \%$ to $0 \%$ with a small peak probably due to the local gas entrainment generated by the reactive zone (Figure 6).

Figure $8:$ Temperature histories on the longitudinal axis of the room $(1.25 \mathrm{~m}$ from the floor)

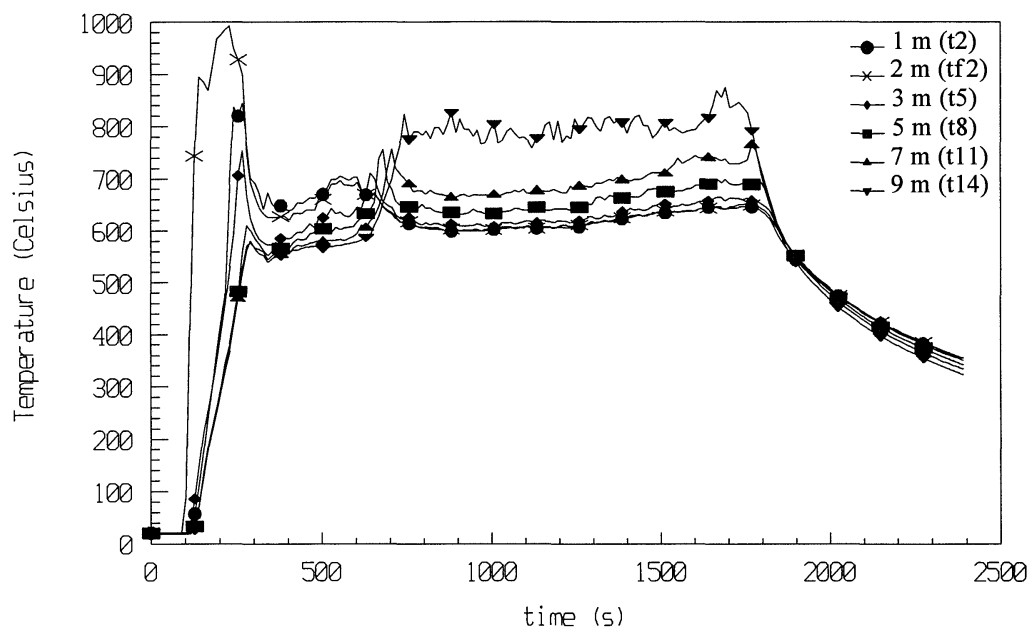


Figure 9 : The main steps of a real scenario for a ghosting flame

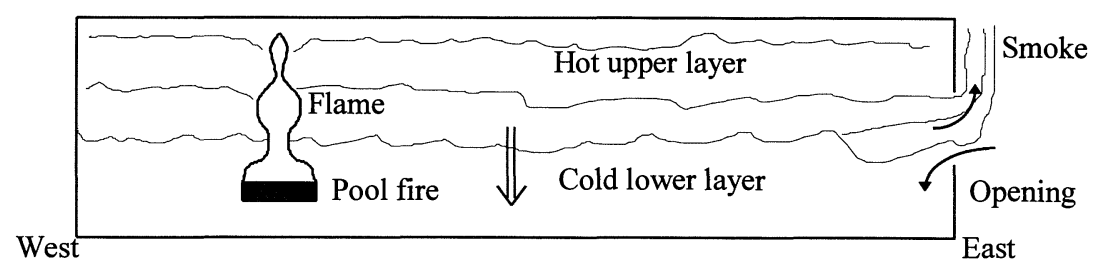

Step a : $t=90 \mathrm{~s}$ (ignition of the pool fire) to $300 \mathrm{~s}$.

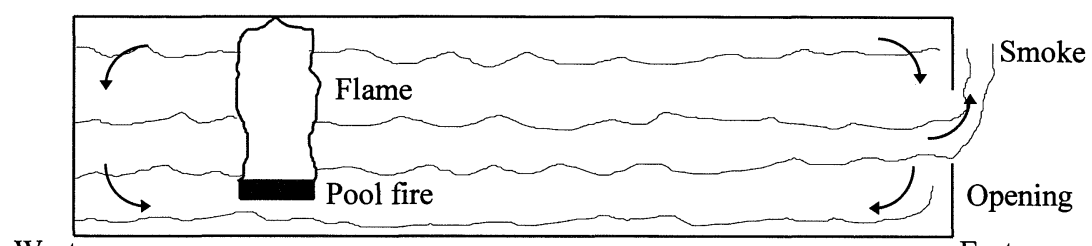

West

Step $b: t=300 s$ to $600 s$.

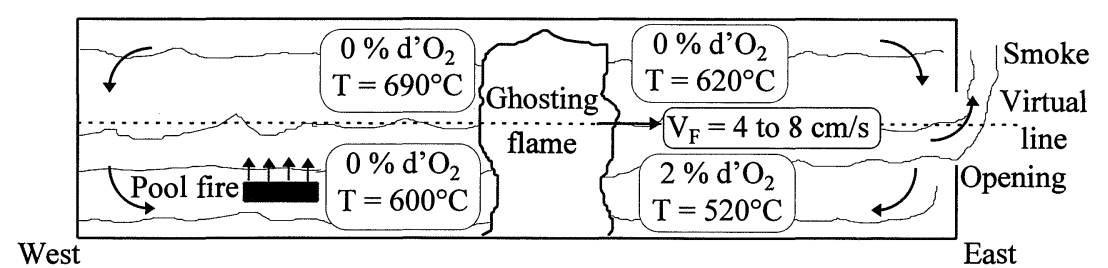

Step $c: t=600 s$ to $750 s$.

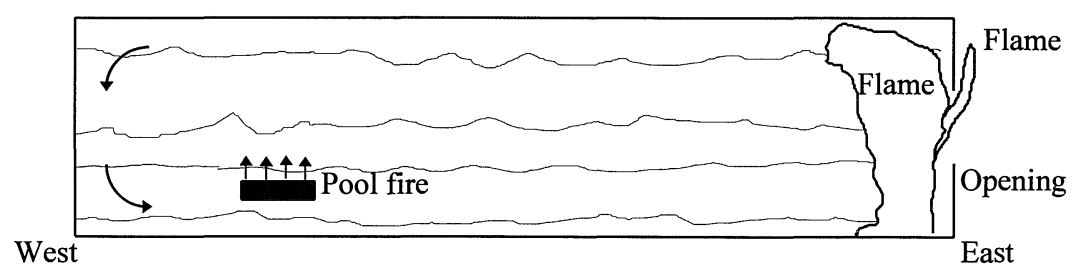

Step $d: t=750 s$ to $1720 s$.

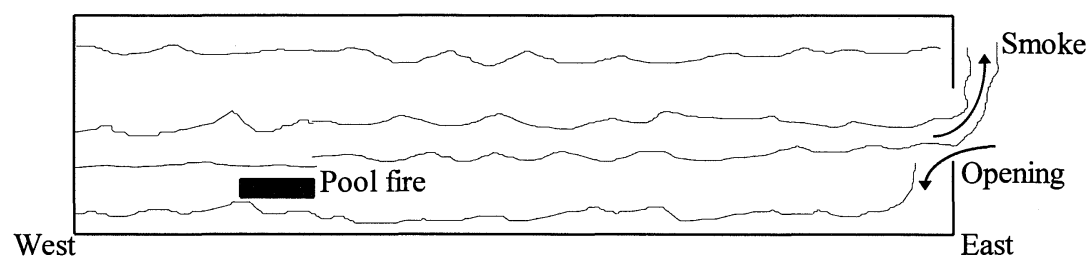

Step $\mathrm{e}: \mathrm{t}=1720 \mathrm{~s}$ and so on. 
If the $\mathrm{CO}_{2}$ concentration remains constant in the upper zone during this period, the $\mathrm{CO}_{2}$ concentration reaches $15.5 \%$ in the lower zone (higher than in the upper zone) and remains constant after the passage of the reactive zone (Figure 6). Thanks to the video camera located at the opening of the compartment, the smoke coming from the room becomes clearer and less thick just before the flame appears. Then, the flame shows yellow packets of reactive gases rising from the floor towards the ceiling. These visual observations are in agreement with the fact that the reactive zone probably moved through the first lower half of the room only because the lower zone had an oxygen volume fraction more than $0 \%$. Then the flame stabilizes at the opening and most flammable gases burn inside the room. A few packets of reactive gases are released through the opening but the flame length visible above the opening does not exceed by one the height of the opening (visual observation).

During the fourth step ranging from $t=750 \mathrm{~s}$ to $t=1720 \mathrm{~s}$ (noted step $d$ in Figure 9), the flame is located at the opening and seems to be quasi-stationary. Due to the hot gases released by the flame in the room, convective motions can supply enough energy to the liquid fuel to pyrolyse it until depletion. The $\mathrm{O}_{2}$ and $\mathrm{CO}_{2}$ concentrations remain constant, respectively $0 \%$ and $13 \%$ in the upper zone and $0 \%$ and $15.5 \%$ in the lower zone (Figure 6). This means that the fire located at the opening of the compartment is supplied with unburnt flammable gases mixed to combustion products for the rich side (compartment side), and with fresh air coming from the JUPITER facility for the poor side. This flame is characteristic of a diffusion flame. Finally the temperatures observed in the room only increase slightly over time, due to the accumulation of hot gases in the compartment and the limitation of cold air exchange with the JUPITER facility (Figures 7 and 8).

During the fifth and last step ranging from $t=1720 \mathrm{~s}$ until the cooling of the room (noted step e in Figure 9), the video camera shows the progressive decrease of the fire intensity at the opening. The flame extinction can be estimated about $1740 \mathrm{~s}$. Consequently, all the temperatures in the room drop very quickly (Figures 7 and 8) and more particularly in the lower zone due to the fresh air flows coming from the JUPITER facility into the compartment through the opening. This phenomenon is called the gravity current effect and is described by Fleischmann et al $[9,10]$. The $\mathrm{CO}_{2}$ and $\mathrm{CO}$ concentrations decrease nearly as quickly while the $\mathrm{O}_{2}$ concentrations increase in the compartment (Figure 6). At the same time, the room pressure decreases as the room temperature decreases (Figure 5).

\section{CONCLUSION}

The real scenario presented in this paper shows the possible existence of a flame or at least of a reactive zone under extreme conditions $\left(0_{2} \% \approx 2 \%\right.$, compartment temperatures $>560^{\circ} \mathrm{C}$ ) that may lead to a flame propagation from the fuel tank towards the opening of the fire room covering up to $8 \mathrm{~m}$ at a velocity ranging from 4 to $8 \mathrm{~cm} / \mathrm{s}$. The reactive zone observed during this experiment seems to present important similarities with the ghosting flame phenomenon previously studied by Sugawa et Al. This study is, mainly, an industrial approach which only describes a phenomenon that is hardly known at present. However, it concerns safety in an industrial facility in which conditions close to this study are very likely (poor ventilation, high temperature). Complementary and systematic studies on the subject would lead to a better understanding of a ghosting fire, its consequences and the solutions to be implemented to prevent it. 


\section{ACKNOWLEDGMENTS}

This work was carried out as part of the program financed by the IPSN (Protection and Nuclear Safety Institute).

\section{REFERENCES}

1. Quintiere J. G., « Compartment Fire Modeling », SFPE Handbook, 2nd Edition, Section 3, pp 125-133, (1994).

2. Backovsky J., Foote K. L., Alvares N. J., « Temperature Profiles in Forced-Ventilation Enclosure Fires ", Fire Safety Science - Proceeding of the Second International Symposium, pp 315-324, (1989).

3. Beyler C., " Analysis of Compartment Fires with Overhead Forced Ventilation », Fire Safety Science - Proceeding of the Third International Symposium, pp 291-300, (1991).

4. Orloff L., Modak A. T., Markstein G. H., "Radiation from Smoke Layers », 17th Symposium International of Combustion, The Combustion Institute, pp 1029-1038 (1979).

5. Sugawa O., Kawagoe K., Oka K., Ogahara I., « Burning Behavior in a Poorly Ventilated Compartment Fire - Ghosting Fire », Fire Science \& Technology, vol 9, n², pp 5-14, (1989).

6. Beyler C., « Flammability Limits of Premixed and Diffusion Flames », SFPE Handbook, 2nd Edition, Section 3, pp 147-159, (1994).

7. Morehart J. H., Zukoski E. E., Kubota T., « Characteristics of Large Diffusion Flames Burning in a Vitiated Atmosphere ", Fire Safety Science - Proceeding of the Third International Symposium, pp 575-583, (1991).

8. Morehart J. H., Zukoski E. E., Kubota T., « Chemical Species Produced in Fires Near the Limit of Flammability », Fire Safety Journal, n¹9, pp 177-188, (1992).

9. Fleischmann C. M., Pagni P. J., Williamson R. B., « Exploratory Backdraft Experiments », Fire Technology, n²9, pp 337-348, (1993).

10.Fleischmann C. M., Pagni P. J., Williamson R. B., "Quantitative Backdraft Experiments », Fire Safety Science - Proceeding of the Fourth International Symposium, pp 337-348, (1994).

11.Drysdale D., An Introduction to Fire Dynamics, John Wiley and Sons, New York (1985). 